\title{
WHAT POLYGLOTS TALK ABOUT: TRANSCRIBING THE ROUND TABLE DISCUSSION ON POLYGLOTTERY AND EDUCATION HELD IN NEW YORK CITY, 2013
}

\author{
Stepan Kulakov \\ Moscow University for the Humanities \\ 5, ul. Yunosti, Moscow, 111395, Russia
}

\begin{abstract}
This paper is based on the experience gained while transcribing the audio recording of the round table discussion on polyglottery and education held at the international conference Multilingual Proficiency: Language, Polyglossia and Polyglottery (New York City, 2013). The discussion covered such topics as the definitions of a polyglot, the measurement of language knowledge, the phenomenon of switching languages in speech and the implementation of polyglots' experience in language education systems. A summary of the discussion is provided, the key ideas of the participants are pointed out, and some personal observations on the matter are shared, including the difficulties confronted during the process of transcription.
\end{abstract}

Keywords: polyglot, polyglottery, multilingualism, language learning, code-switching, education

For citation: Kulakov, S. (2021). What Polyglots Talk About: Transcribing the Round Table Discussion on Polyglottery and Education Held in New York City, 2013. Linguistics \& Polyglot Studies, 7(4), pp. 53-56. https://doi.org/10.24833/2410-2423-2021-4-28-53-56

7 his study is based on the experience gained during the transcription of the round table discussion at the 2013 International Conference on Multilingual Proficiency: Language, Polyglossia and Polyglottery in New York City. This event is notable for being the first academic discussion on polyglottery featuring both linguists and polyglots. It was a precursor of subsequent academic round tables on polyglottery and panel discussions at the Polyglot Conferences and Polyglot Gatherings. Amongst the people involved were professors Alexander Arguelles, Hikaru Kitabayashi, Leonard Ashley and Wayne Finke, historian Marcelline Block, and young polyglots Alex Rawlings and Timothy Doner. The source of the material is the audio recording of the discussion made by Grigory Kazakov and acquired from him for the purpose of transcription ${ }^{1}$.

\footnotetext{
1 The transcript of the round table is published in the present volume (editor's note).
} 
Polyglottery as a topic of this research is defined as consciously obtained fluency in multiple languages. Its difference from related terms such as polyglossia (the usage of multiple languages in one geographic area) and multilingualism (fluency in multiple languages that is obtained naturally in childhood) should be noted [2, p. 8290]. Olessia Jouravlev et al. define polyglots as "individuals who have acquired at least some of the languages after the critical period" [1, p. 62]. Polyglottery is currently a growing sphere of scientific research: 25 articles on the topic have been published so far, besides books and conference proceedings. A recent proof of the academic interest in polyglottery is the round table Psycholinguistic Study of Polyglottery and Its Application for Language Learning at the $12^{\text {th }}$ Congress of the International Society of Applied Psycholinguistics held on June 5, 2021 [3, p. 181-188], [4].

Polyglots are the target of this study not because they know multiple languages but because they have gone through the process of learning them. The focus on learning is important because it highlights the process. Each polyglot has gone through a different kind of process, but, apart from the ending result being a success, they do have a few features in common. As evident from the transcription, self-education is a key aspect of polyglottery. Since all polyglots use different kinds of self-education, it must be noted that an individual approach is crucial. These are only the most basic principles that can help other people on their way to learning languages. Accumulating polyglots' knowledge in language learning is important because, if applied, it may significantly raise the efficiency of the current language education system.

The key topics the polyglots discussed during the round table session were as follows.

What is a polyglot? One of the main issues of polyglottery is defining the term itself. Although it is quite popular to determine whether a person is a polyglot or not by the number of languages he/she knows, polyglots are quite unanimous in the opinion that it should not be the case. Leonard Ashley, for example, suggests that almost everyone on the planet is a polyglot, since "everybody manages various dialects and different languages". His other point is that "you have to love the idea" of learning languages. Alexander Arguelles is convinced that a polyglot cannot be defined by the number of languages acquired, being a person seeking to find new effective ways to learn a language and capable of freely conversing with a native speaker instead. Hikaru Kitabayashi believes that knowing three languages at the academic level can be considered polyglottery. Touching upon the earlier discussion, Grigory Kazakov thinks that cognitive effort in learning different kinds of languages should be measured and provides a working definition of a polyglot as a "a person who is devoted to language learning and to the acquisition of as many languages as possible".

What does it mean to "know" a language? This is the problem that puzzles not only polyglots alone. The polyglots have had a handful of opinions on the matter at the round table whilst still struggling to come up with one specific definition. The ability to talk to a native speaker in a fluent way on a variety of topics was mentioned as one of the possible ways of defining it. Alexander Arguelles uses a conference participant as an example of somebody who knows a foreign language because he functioned in it throughout the whole day. Hikaru Kitabayshi thinks that one knows a language when they can converse in it at the academic level. Leonard Ashley's opinion on the matter is that to know a language one has to "speak with native speakers and understand everything they say", as it is the ability to use the spoken language that is of primary significance. Alex Rawlings agrees, though he is not quite sure if there is "a reliable way of measuring a universal ability of learning languages" as he believes he does not speak the other languages he has been learning at the same level he speaks his mother tongue. Wayne Finke insists that it is important to distinguish between knowing languages at the scholarly level and being able to keep up a conversation in them.

Switching languages in action. The polyglots also discussed the phenomenon of switching languages in action, which is something bilingual people tend to do. For example, people tend to use their native language in the situation of great grief or joy to express their feelings more accurately. Timothy Doner mentions a study that took place on the subway in New York City. It showed that people there tend to switch to their native tongue to express negative emotions. Another example of his refers to a woman who switches from formal Arabic to the Egyptian dialect when emotionally attached to the topic of discussion. Marcelline Block's example touches upon the Marseille Trilogy, filmed in 1930s, where characters switch from formal French to Provençal when having an emotional reaction. Yet another example by Alexander 
Arguelles about bilingual Korean-American sisters who switch to Korean while arguing further proves the connection between code switching and emotions.

How can polyglottery be implemented in the education system? The current language-teaching system is far from ideal. That is why applying methods from people who learn languages constantly and successfully can be beneficial for language learners. Immersion was mentioned as one of the ways to go. Putting a person into circumstances where they have to communicate in a foreign language produces results, as Harri Ruohonen proves with the example of his grandfather who was forced to learn Russian facing hunger. Alexander Arguelles pays attention to the importance of a personal approach, as some methods may work for one kind of people and others may not. Timothy Doner brings up an important point that the ability of adults to look at the language at the scientific level should not be overlooked. By way of example he mentioned that pure immersion, important as it is, cannot lead one to understand Arabic in all its complexity. Leonard Ashley's suggestion is to learn the spoken language first and use the gathered knowledge to get to the grammar, not the other way round. Alex Rawlings disagrees with that view. One of the points he makes is that language cannot be taught like science, as "language learning is far more than an hour and twenty minutes a week". He also points out the importance of exposure to the foreign language and gives the example of Nordic countries that have subtitles for foreign films instead of dubbing. Hikaru Kitabayashi thinks that it is not language teaching that is heavily flawed but language learning, and that one should look more into this field.

Motivation for learning languages. It is not only the "love" for languages that drives polyglots. However, Leonard Ashley and Wayne Finke are convinced that you have to have passion to learn. The former talks about his experience of learning a dead language, Cornish, as a graphic example. The latter was driven into learning languages by listening to foreign radio stations when he was a child. Timothy Donner is fascinated by the "interplay between history and language". Hikaru Kitabayashi talks about the troubles of the monolingual approach to history and how knowing foreign languages would help with that, thus offering a more pragmatic perspective. Harri Ruohonen is also pragmatic as he claims that it is the things he could do with languages that drove him, not languages themselves. As Alexander Arguelles says, good motivation also leads to better overall results. He was turned onto language learning by his curiosity about the books on different languages his father had at home. So, even though it is usually the love and passion for languages that drive polyglots, purely pragmatic advantages are being thought of as well.

During the discussion of these and other topics, some ideas were developed that deserve recognition. One of them is the question whether one can really know a foreign language just as well as his mother tongue. Harri Ruohonen is sure that despite only starting to learn English when he was seven, he is, in fact, bilingual, as he has no difficulties in conversing in it. Alexander Arguelles, however, says that even bilingual people do not use their two languages to the same extent. Another interesting topic in the discussion was numbers and counting in different languages. Alfred Friedlander draws attention to the fact that people tend to count in their mother tongue when talking in English. Marcelline Block points out that her mother would always count in French while being fluent in English and living in an English-speaking country.

Transcribing the audio recording proved to be quite challenging due to the transcriber's limited language expertise, technical imperfections of the recording itself and a variety of different accents of the participants. Those aspects, however, ensured gaining valuable language experience.

The topics raised during the round table session and the points made by the participants largely formed the agenda of subsequent polyglot events and are still up-to-date in the polyglot community, where some of the 2013 conference participants (Alexander Arguelles, Alex Rawlings and Grigory Kazakov) have played an active role. Observing the development of polyglots' ideas on these issues should make it possible to see if the polyglot agenda has changed over the years, which constitutes the immediate perspective of this study.

(C) S. Kulakov, 2021 


\section{References}

1. Jouravlev, O., et al. The small and efficient language network of polyglots and hyper-polyglots. Cerebral Cortex, 2021, vol. 31, no. 1. P. 62-76. DOI: 10.1093/cercor/bhaa205.

2. Kazakov, G. Research on polyglottery: sources of data. EDULEARN21 Proceedings. 2021. P. 8290-8296. DOI: 10.21125/edulearn.2021.1670.

3. New Perspectives in Psycholinguistic Research: Language, Culture, Technologies. Online 12th ISAPL International Congress. June 3-5, 2021. Book of Abstracts (L. Scliar-Cabral et al. eds.). ISAPL, 2021. 246 p.

4. Nikulicheva, D. Krugly stol "Psikholingvististicheskoe issledovanie poliglotii i ego primenenie dlia tseley izucheniia iazykov" [Round table "Psycholinguistic study of polyglottery and its application for language learning"]. Journal of Psycholinguistics, 2021, 2 (48). P. 205-209. DOI: 10.30982/2077-5911-2021-48-2-205-209.

\section{About the author:}

Stepan Kulakov, BA in Linguistics, is a graduate of Moscow University for the Humanities. Research interests: polyglottery, language learning, English accents.

E-mail: stepacool@gmail.com 